Thorax (1965), 20, 8.

\title{
Bronchial closure
}

\author{
GOR D O N D. JACK
}

From Baguley Hospital, Manchester

A bronchial fistula from a main bronchus is an avoidable complication of lung resection. There are three factors that may contribute to the breakdown of a suture line: an inadequate blood supply, tension on the sutures, and infection. Not one of these need occur. The technique of bronchial closure described below makes a fistula from a major bronchus a very rare occurrence.

\section{MATERIAL}

Table I lists the type of resection carried out in the 1,100 operations considered in this report. Of

T A B L E I

\begin{tabular}{|c|c|c|c|c|c|}
\hline $\begin{array}{c}\text { Type } \\
\text { of Resection }\end{array}$ & $\begin{array}{l}\text { Tuber- } \\
\text { culosis }\end{array}$ & Cancer & $\begin{array}{c}\text { Bronchiec- } \\
\text { tasis }\end{array}$ & Others & Total \\
\hline $\begin{array}{l}\text { Pneumonectomy } \\
\text { Left } \\
\text { Right }\end{array}$ & $\begin{array}{l}62 \\
25\end{array}$ & $\begin{array}{l}169 \\
169\end{array}$ & $\begin{array}{r}19 \\
3\end{array}$ & $\begin{array}{l}2 \\
1\end{array}$ & $\begin{array}{l}252 \\
198\end{array}$ \\
\hline 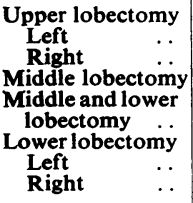 & $\begin{array}{r}74 \\
83 \\
1 \\
3 \\
9 \\
6\end{array}$ & $\begin{array}{r}52 \\
71 \\
5 \\
55 \\
32 \\
42\end{array}$ & $\begin{array}{r}9 \\
10 \\
32 \\
6 \\
113 \\
28\end{array}$ & $\begin{array}{l}1 \\
4 \\
1\end{array}$ & $\begin{array}{r}136 \\
168 \\
39 \\
64 \\
164 \\
79\end{array}$ \\
\hline Total & 263 & 595 & 220 & 22 & 1,100 \\
\hline
\end{tabular}

the tuberculous patients, $36.8 \%$ were known to be drug-resistant to at least one of the standard antituberculous drugs; $42 \%$ had a positive sputum and had been on an unsatisfactory pattern of drug treatment. The cases are all those who had major lung resections during the period 1953 to 1963 inclusive. During this time 196 segmental resections were also carried out, but these cases have only been included when such resections were combined with a lobar resection, and they have not been separately listed.

\section{ANAESTHETIC TECHNIQUE}

In the majority of adults a Carlen's tube has been used for anaesthesia since early 1955 as this facilitates the removal of bronchial secretions. It may also make surgery easier by allowing one lungì anaesthesia for part of the time and particularly? during bronchial closure. When a Carlen's tubeio cannot be used, as in children, a short period of을 extra inflation is given just before the bronchus $\rightarrow$ is opened. During the period of bronchial closure $c$ oxygenation by diffusion is adequate. If oxygena-כ tion becomes inadequate the bronchial opening is temporarily closed by a swab, and a period of normal pulmonary inflation is given; inflations is then stopped and the bronchial closure is com- $-\mathrm{T}$ pleted. When a Carlen's tube is used during aO right pneumonectomy the hook is removed so that it does not interfere with the tracheal closure. When used in relation to a left pneumonectomy the Carlen's tube is withdrawn into the trachea. $\stackrel{\odot}{\Omega}$ In children an ordinary endotracheal tube is used $\stackrel{2}{\Rightarrow}$

\section{SURGICAL PRINCIPLES}

To avoid damage to the blood supply of the bronchus a clamp is not applied on the proximal bronchus. The dissected bronchus is divided about $1 \mathrm{~cm}$. beyond the carina distal to which the re- $x$ section is to be made. This wide open bronchus 3 is carefully inspected and suitably trimmed so asio to produce a short and mobile bronchial flap which is then sutured to the opposite bronchial wall flush with the proximal carina. By this means ${ }^{-}$ all tension is avoided and no stump is left. The bronchial suture line is potentially infected, and it is therefore important to suture the immediately related tissues over the site of bronchial closuren so that there is no dead space left where blood clot could collect and precipitate infection. Since ${ }^{\omega}$ the beginning of June $19562 / 0$ or $3 / 0$ chromice catgut on atraumatic needles has been the onlye suture material used in relation to the majoros bronchi. Before that date silk or fine linen thread was used. To illustrate the technique a detailed description of four routine resections is set outत्D below.

RIGHT PNEUMONECTOMY The right main bronchuse is dissected free of all glands up to the mainf carina, and $4 \mathrm{~cm}$. of the lower trachea is exposed 
FIG. 1. Right pneumonectomy: $(A)$ exposure; $(B)$ preparation of the trachea and bronchus; $(C)$ suture of the trachea; (D) method of covering the bronchus by suturing the oesophagus to the pericardium.
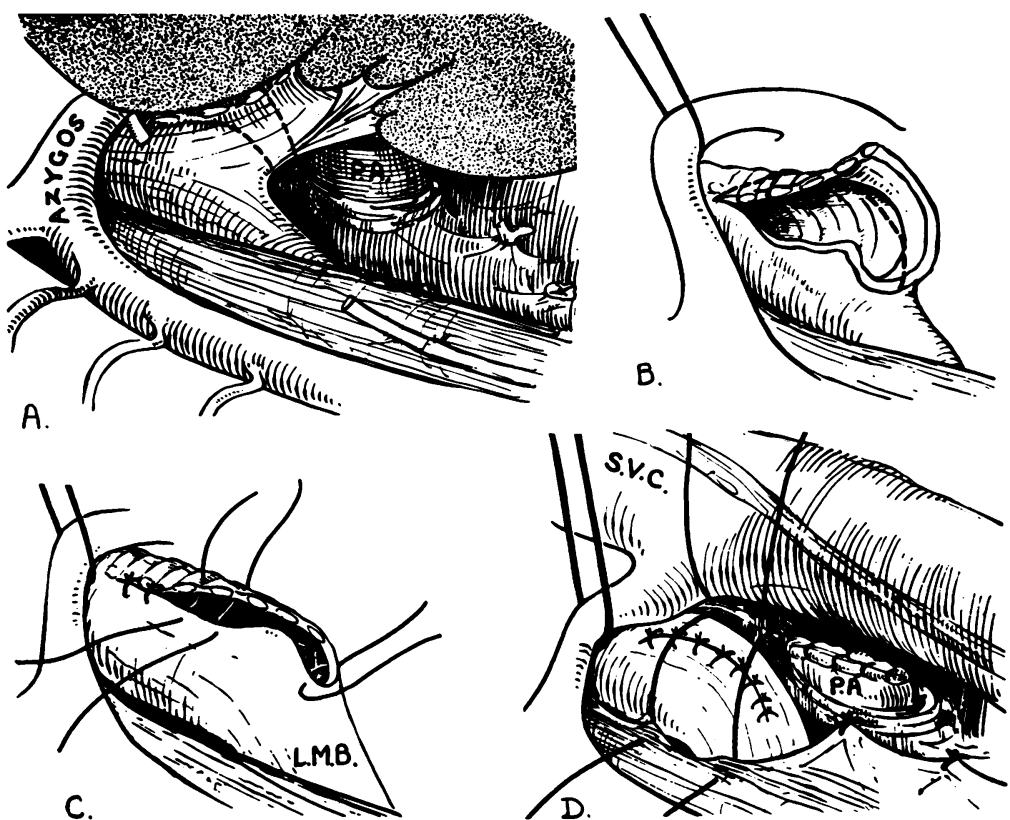

usually without division of the azygos vein (Fig. $1 \mathrm{~A})$. The right main bronchus is divided $1 \mathrm{~cm}$. beyond the main carina, and the lung is removed or retracted with clamping of the distal bronchus to prevent soiling of the pleura if the lung is not ready for removal. The bronchial closure is carried out entirely proximal to the main carina; it is therefore a tracheal closure. The soft posterior wall of the right main bronchus and trachea is incised at the extreme posterior tips of the cartilaginous rings. This incision is carried up the trachea for 3 to $4 \mathrm{~cm}$. according to circumstances. From the upper end of this incision a portion of the right side of the lower tracheal rings is excised down to the main carina (Fig. 1 B). This leaves a gap which is closed by swinging forward the prepared and completely flexible posterior flap, which is now sutured to the rigid tracheal portion. There is no tension if these flaps have been correctly made.

In the early days of using this technique, it is better to make the posterior flap a little too large and trim it secondarily when the first two or three sutures have been inserted. The first two sutures are placed at the superior and inferior ends of the opening in the trachea, and thereafter five to seven additional stitches are inserted (Fig. 1 C). The oesophagus is displaced slightly forward over the tracheal closure line by suturing its muscle layer to the pericardium behind the lowest $3 \mathrm{~cm}$. of the superior vena cava and the pulmonary artery (Fig. 1 D).

LEFT PNEUMONECTOMY This is perhaps the most difficult lung resection from the point of view of perfect bronchial closure. When the area has been dissected to expose the bronchus, a clamp is placed across the distal bronchus at the level of the upper lobe bronchus, and the bronchus beyond it is divided and the lung removed (Fig. 2 A). This is necessary to get adequate exposure to the trachea under the aortic arch. At this point the patient is rolled slightly on to his back or the table is rotated whilst the anaesthetist withdraws the Carlen's tube. At the same time all secretions are sucked out of the left main bronchus. The bronchus is dissected up to the main carina, the carinal glands are removed, and the lowest $3 \mathrm{~cm}$. of the trachea is exposed. With retraction of the aorta it is now possible to insert a suture into the lateral tracheal wall directly above the main carina. This suture is left long and regarded as a 'stay' suture. A second 'stay' suture is inserted through the main carina as was done for a right pneumonectomy. A posterior flap is cut from the trachea and first centimetre of the posterior wall of the left main bronchus, and a start is made in dividing the cartilaginous part of the trachea above the origin of the left main bronchus (Fig. $2 \mathrm{~B})$. The soft posterior wall of the trachea is 

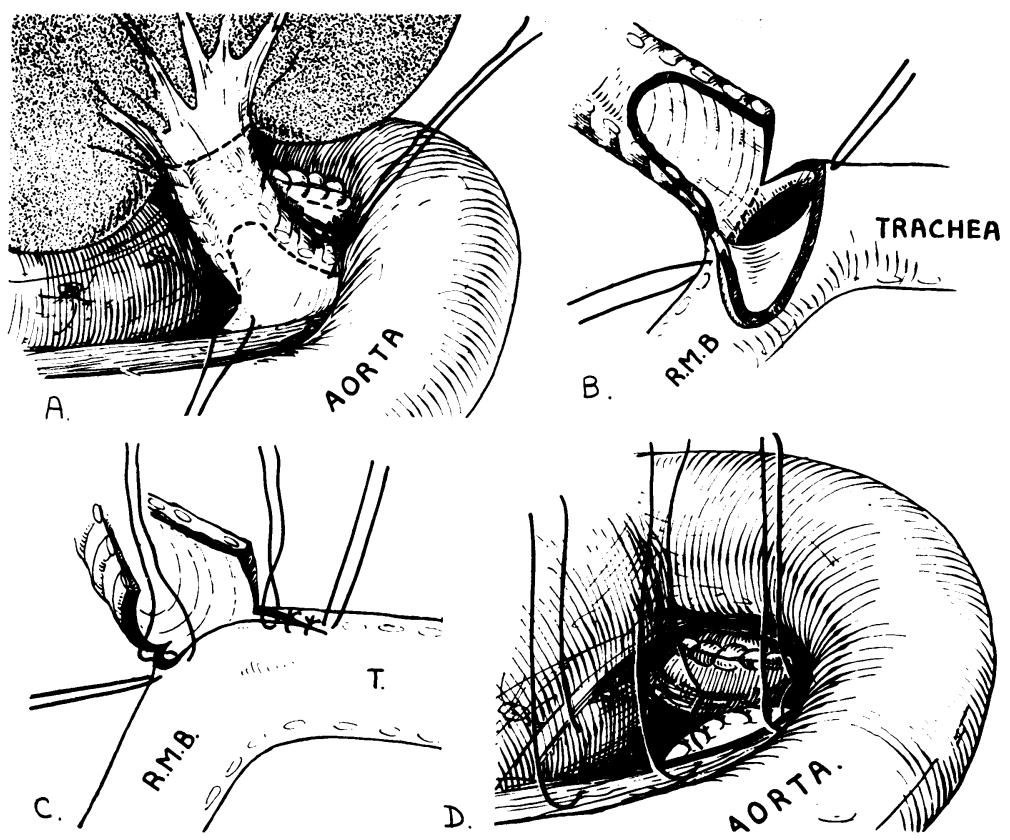

FIG. 2. Left pneumonectomy: $(A)$ exposure; $(B)$ preparation of the trachea and bronchus; $(C)$ suture of the trachea; $(D)$ the oesophagus is being sutured to the pericardium behind the pulmonary artery and over tracheal closure.

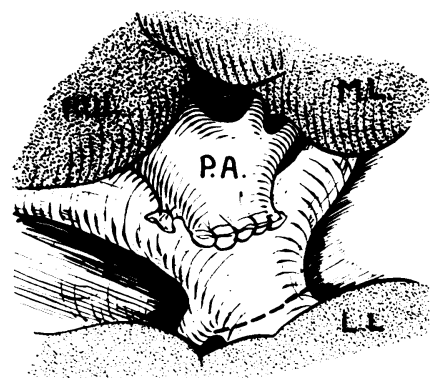

A.

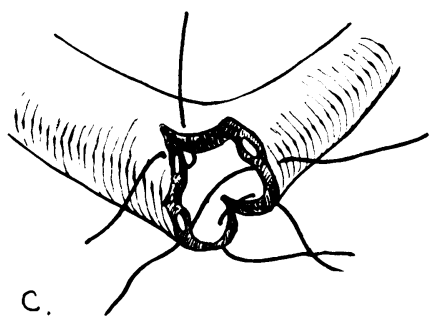

B.
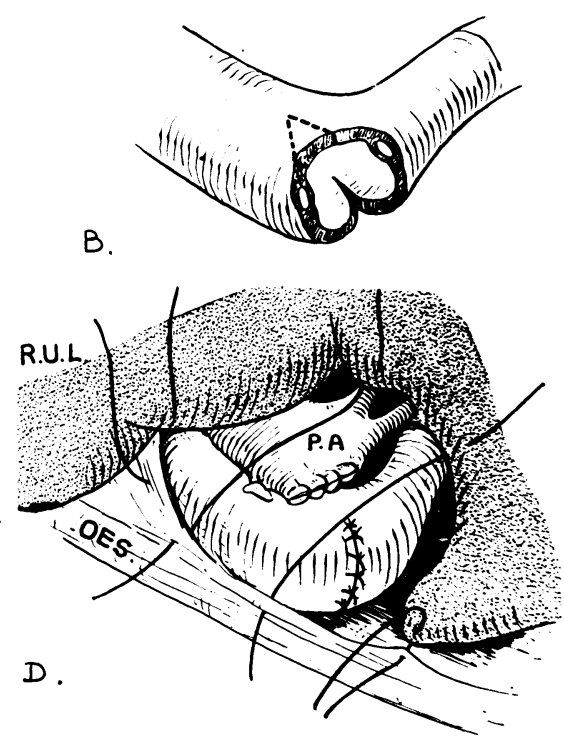

FIG. 3. Right lower lobectomy: $(A)$ exposure showing artery sutured and dotted line of primary bronchial division through the origin of the apical lower bronchus; (B) bronchus cut back preparatory to suturing middle lobe bronchus on to the end of the stem bronchus; $(C)$ suturing bronchus; $(D)$ burying stump by suturing the peri-oesophageal tissues to the lung. 
sutured to the divided edge of the trachea before the main bronchus is completely cut away from the trachea. Three more stitches are inserted and then, using the 'stay' sutures to hold up the trachea and main carina, the rest of the main bronchus is cut off and a further three or four stitches are inserted (Fig. $2 \mathrm{C}$ ). This leaves the suture line with an occasional trace of tension, which is immediately relieved when the 'stay' sutures are released and the trachea is allowed to retract into the mediastinum. The oesophagus is sutured over the tracheal closure to the pericardium behind the pulmonary artery with about four stitches. Occasionally the mediastinal pleura is also closed over the oesophagus (Fig. 2 D).

RIGHT LOWER LOBECTOMY The lower part of the stem bronchus and the lower and middle lobe bronchi are exposed. The artery has been divided and sutured or ligatured. The bronchus to the lower lobe is divided slightly obliquely through the apical lower bronchus (Fig. $3 \mathrm{~A}$ ). The bronchus is opened, and dissection shows that the middle lobe bronchus is closely adherent to the anterior wall of the stem bronchus for about $1 \mathrm{~cm}$. beyond its origin. This is dissected up to the carina of the middle lobe bronchus. The postero-lateral wall of the intermediate bronchus is found to be soft and, by excising two wedges of bronchus from the medial and lateral aspects, a flap is formed which is lightly sutured to the carina of the middle lobe bronchus (Figs. $3 \mathrm{~B}$ and $\mathrm{C}$ ).

Again the peribronchial tissues are sutured to the oesophagus and pleura posteriorly. Inferiorly, the pericardium, oesophagus, and peribronchial tissues are all brought together over the bronchial closure line, so completely covering this area (Fig. 3 D).

LEFT UPPER LOBECTOMY The dissection of the hilum of the lung is carried out to allow the artery to be retracted backwards and slightly upwards, exposing the stem bronchus and the origin of the left upper bronchus (Fig. 4 A). The upper lobe bronchus is divided about $0.5 \mathrm{~cm}$. beyond its origin. This allows one to see the precise site of the left upper carina (Fig. $4 \mathrm{~B}$ ). The bronchus is trimmed back to the carina in relation to the inferior lip of the bronchotomy, and small wedges of the stem bronchus are excised from its anterior and posterior walls. Sutures are inserted in the most medial aspect of each of these wedges, and these sutures are tied (Fig. $4 \mathrm{C}$ ). This brings the lips of the bronchus together, allowing the lower lobe to swing up slightly. This is also encouraged by division of the inferior pulmonary ligament at

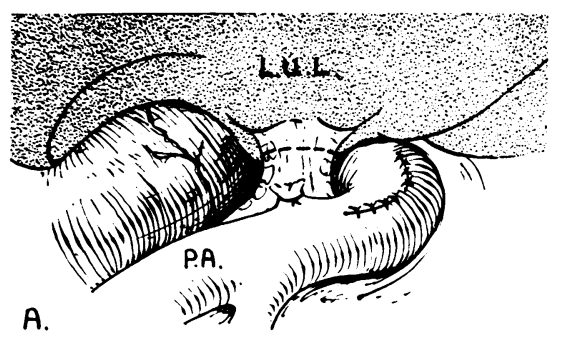

B.
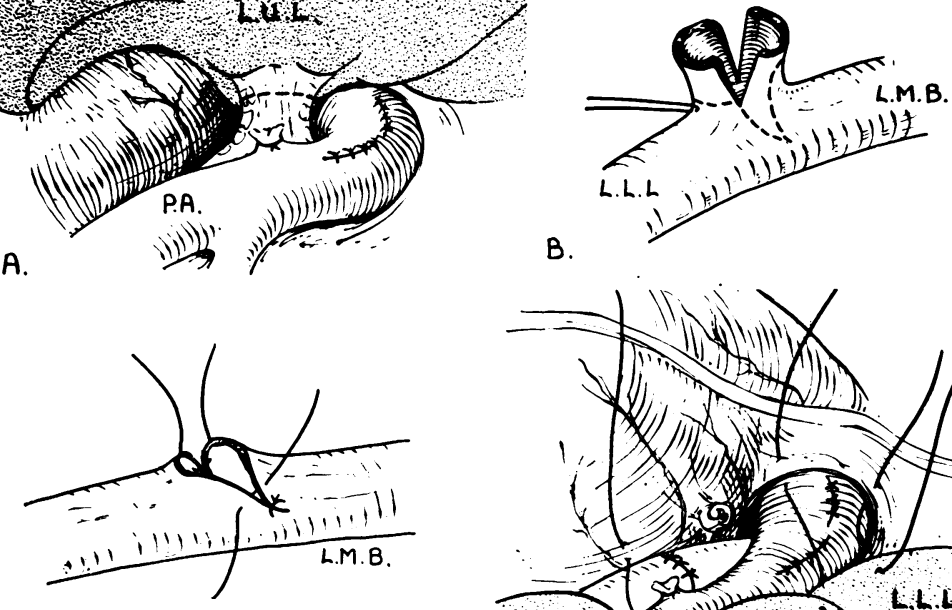

C.

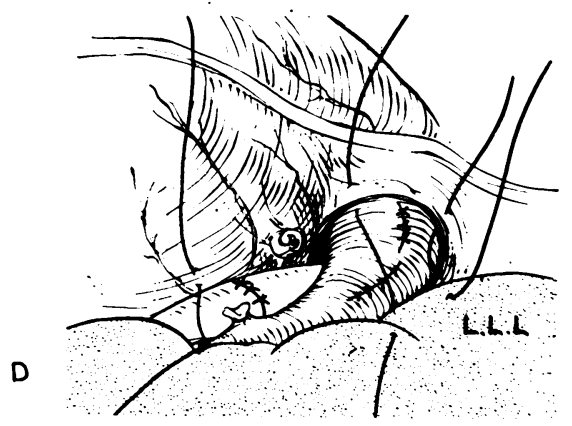

FIG. 4. Left upper lobectomy: $(A)$ exposure with arteries sutured and upper lobe bronchus exposed; $(B)$ method of trimming bronchus with wedges out of stem bronchus; $(C)$ closure; $(D)$ covering of bronchial suture line by suturing pericardium to lung. 
an earlier stage. The upper lip of the bronchotomy opening is trimmed to meet the lower lip, and three or four more stitches are inserted. The parapericardial fat and pericardium are sutured over the bronchial closure line by three stitches to the peribronchial fibrous tissue. This completely closes the area and brings the left upper lobe up and slightly forward, which is the final position it will occupy post-operatively.

\section{DISCUSSION}

The privately circulated report of the joint committee of the British Tuberculosis Association and the Society of Thoracic Surgeons on the results of major surgery for pulmonary tuberculosis revealed a broncho-pleural fistula rate of 7.4 in 973 patients who underwent lobectomy or pneumonectomy for pulmonary tuberculosis. Gifford and Waddington (1957), discussing lung resection for carcinoma, reported that of 101 post-operative deaths eight were due to fistulae, and of 204 patients who died subsequently $8 \cdot 8 \%$ had broncho-pleural fistulae. Since the total series comprised 464 patients this represents a fistula rate of $5 \cdot 6 \%$. Bromley and Szur (1955) reported 66 lung resections after radiotherapy and in these circumstances the fistula rate was $20 \%$. The conditions may have been unfavourable in these patients but they note that 'no formal procedure was adopted in this series for giving added cover to the stump of the bronchus'. Similar fistulae rates have been reported by other authors for both tuberculous and non-tuberculous disease.
In this series only one broncho-pleural fistula $\stackrel{\vec{F}}{\vec{\rho}}$ occurred and this developed in association with an acute febrile illness six months after a right pneumonectomy for pulmonary tuberculosis. The $\frac{\bar{\Phi}}{\vec{D}}$ patient had been well in the intervening period, $\stackrel{\varnothing}{\varrho}$ and the empyema was a staphylococcal one. At a further operation the trachea was reclosed and $a \vec{a}$ thoracoplasty was done. At this operation no histological evidence of tuberculosis was present. $\vec{\omega}$

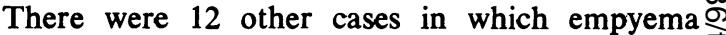
occurred. In six of these there had been known $\vec{x}$ soiling of the pleura at the time of operation. In i the other seven cases it was an unexpected complication. All were carefully examined with the $\infty$ possibility of fistula in mind, but in none was such 음 a fistula found. In 1956 a change to catgut as a suture material was made and since then no fistula has occurred.

This report shows that broncho-pleural fistula is avoidable.

\section{SUMMARY}

A method of bronchial closure which avoids bronchial fistula is described and is supported by the results of 1,100 lung resections.

My thanks are due to Miss Perry, of Crumpsall Hospital, for her excellent illustrations.

\section{REFERENCES}

Bromley, L. L., and Szur, L. (1955). Combined radiotherapy and resection for carcinoma of the bronchus, Lancet, 2, 937.

Gifford, J. H., and Waddington, J. K. B. (1957). Review of 464 cases of carcinoma of lung treated by resection. Brit. med. J., 1, 723 . 